\title{
The Risk Factors That Lead to Addiction and Relapse among Addicted Patients
}

\author{
Taysser Ibrahim Helmy ${ }^{1}$, Maaly Ibrahim El Malk ${ }^{2}$, Gihan Mohamed \\ Salem $^{3}$ \\ ${ }^{1}$ Instructor of Psychiatric / Mental Health Nursing Technical Institute-Imbaba, \\ ${ }^{2}$ Assistant Professor of Psychiatric Mental Health Nursing, Faculty of Nursing, \\ Monofia University, Menoufia University, ${ }^{3}$ Lecturer of Psychiatric, Mental Health \\ Nursing, Faculty of Nursing, , Benha University.
}

\begin{abstract}
Background: Drug addiction is a chronic, relapsing disorder in which compulsive drug seeking and drug-taking behavior persists despite of serious negative consequences. The purpose of this study was to assess the risk factors that lead to addiction and relapse among addicted patient. This study was conducted at Benha and Abassia mental hospitals. A descriptive design was used to achieve the purpose of this study. A purposive sample of 80 adult patients was selected from the hospitals of the above mentioned settings. Three instruments were used for this study as: (1) structured interview questionnaire to assess demographic data about the patient, risk factors of addiction and patient's perception about addiction, (2) Social adjustment scale to measure social adjustment and (3) Social competence scale to measure social competence. Results: the most common risk factors for addiction were psychological problems, weak will power, bad friends, and family problems, pressure at work, physical problem and cigarette smoking respectively., Relapse was higher in male than female with highly statistical significant difference There for, it was concluded that psychological problems bade friends, cigarette smoking and family problems could lead to addiction and relapse. Recommendation: Stress management and assertiveness training program should be provided for those patients to relive their psychological problems, also thy need educational programs and awareness of the dangers of drug abuse and its negative effects on the individual and society
\end{abstract}

Key words: Addiction - Risk Factors -Addict.

\section{Introduction}

Addiction is complex phenomena that defy simple explanation or description. A tangled interaction of factors contributes to an individual's seeking out, using, and perhaps subsequently abusing drugs (National Institute on Drug Abuse, 2010).

Drug addiction is a chronic, relapsing disorder in which compulsive drug seeking and drug-taking behavior persists despite serious negative consequences. Addictive substances either induce pleasant states (euphoria in the initiation phase) or relieve distress. Continued use induces adaptive changes in the central nervous system that lead to tolerance, physical dependence, sensitization, craving, and relapse (Alan \& Leshner, 2008).

Meanwhile, there are no official governmental statistics on the prevalence of addiction and substance uses in Egypt. However, there are multiple sites, such as universities and the National Center for Social \& Criminology Research (NCSCR) that perform many epidemiological studies tracing addiction in Egypt. According to the National Addiction Survey, there is at least half a million addicts in Cairo who need 
treatment (Hamdi, E., Sabry, N., Sedrac, A., and Refaat, O., 2011).

Recent study published by Egypt's National Council for Fighting and Treating Addiction (UNODC, 2010), reported that the majority of drug users were between 15 and 25 years old. Banjo is a type of marijuana that is found in the Middle East, is the drug of choice, Cocaine, Heroin and chemical drugs like Ecstasy and Methamphetamine are also widely available on the local market. About 439,000 children are regular drug users in Egypt. Of the 12.2 percent of Egyptian students who are dependent on drugs, nine percent smokes banjo, three percent prefer hashish and 0.21 percent take heroin or chemical drugs (Hamid, et al., 2013).

Risk factors include those individual or social factors associated with an increased likelihood of a negative outcome. Risk factors can be related to biological, behavioral, and social/environmental characteristics. They include characteristics such as family history, depression or residence in neighborhoods where addiction is tolerated these neighborhoods contain many factors that place the child at risk for addiction (Aldebot, \& Weisman de Mamani, 2009).

The nurse plays a major role in designing nursing process for patients who have substance abuse. Nursing process must focus on psychological as well as physiological managements that begins in the early stages of recovery and continues over time (Greden \& Walter, 2013). Nurses must actually develop and carry out substance abuse prevention services within the treatment programs that can be achieved through accurate assessment of patient's history in order to determine his/her needs and types of rehabilitation program for drug abuse prevention, followed by planning and providing an appropriate nursing intervention and other health care services with frequent evaluation to the effectiveness of such care (Friedman \& Glassman, 2010).

Nurses play a vital role in helping patients undergoing drug rehabilitation. They monitor their progress, help them adjust to life without drugs and teach them how to maintain their health after leaving the rehabilitation center. (Loren Brener, et al., 2010).

Significance of the Problem:

Addiction of substance abuse is becoming an increasing problem in Egypt. Some studies, showed that the majority of youngster in Egypt tried one time or more tramadol tablet and cigarettes. The department of fighting addiction in the Ministry of Health reported that the rate of drug dependence in Egypt was 33\% of the total population (incidence of substance dependency in Egypt, 2013).However (5\%-7\%) drug abuse in Egypt exceeded the accepted international rates (Control \&Treatment of Addiction and Abuse in the Egypt, Hotline, 2013).

Despite the worldwide efforts that has been undertaken to control addiction the rate of ingestion of narcotics ranged between $3.4 \%$ to $6.6 \%$ of adult which range age between $15 \% 64$ years old and this according to international drugs report (UNODC, 2012). According to W.H.O, Hashish is the most common substance that is been used all over world. As the yearly percentage between $2.9 \%$ to $3.4 \%$ among population that their age between 15-64 years old. (Winstock, 2014)

\section{Theoretical and operational definition}

Risk factors of addiction and relapse: Risk factors of addiction and relapse include those individual or social factors associated with an increased likelihood of a negative outcome. Risk factors can be related to biological, behavioral, and social/environmental characteristics. They include characteristics such as family history, depression or residence in neighborhoods where addiction is 
tolerated where the more factors that place the clients at risk for addiction, the more likely it is she or he will experience substance use (Aldebot, \& Weisman de Mamani, 2009).

In the present study risk factor of addiction and relapse were operationally defined by the obtained adduct patient's Social Adjustment score measured by (Abdel Wahab, 1990), the obtained adduct patient's Social competence score measured by (Sarason, Hacker, \& Basham, 1985)and the result of structure interview questionnaire developed by the researcher related to patient's biological, behavioral, and social/environmental characteristics, family history and his perception about addiction.

\section{Methods}

\section{* Purpose of the study:}

The purpose of this study was to assess the risk factors of addiction and relapse among addicted patient at Benha and Abassia mental hospitals.

\section{* Research Questions:-}

1- What are the risk factors of addiction among addicted patient?

2- What are the patient's perceptions about addiction among addicted patient?

3- Is there a relationship between patient's family history, perception abut addiction and relapse?

4- Is there a correlation between relapse and both of social adjustment, and social competence

\section{* Research design:-}

A descriptive correlational design was utilized to fulfill the purpose of this study

\section{* Setting:-}

This study was conducted at two Psychiatric Hospitals; these hospitals were Al Abbassia and Benha psychiatric hospitals. AL Abbassia psychiatric hospital is the oldest and biggest hospital for psychiatric and mental health in Cairo City; Egypt it was built in 1883 on 68 feddans the hospital capacity is 1950 bed, it contain 4 main department. 2 old major department for psychiatric patients one for male which is divided into $10 \mathrm{sub}$ department and the other for female which is divided into 9 sub department. The other 2 new departments each one divided into 6 sub departments which serve psychotic and addict patients. The addiction department contains 120 beds for male, and 27 beds for female, to serve addict patients; the staff provides psychotropic therapies, drug abuse therapy, psychotherapy, support therapy, milieu therapy and CBT.

Psychiatric hospital in Benha City, Qaliubiya Governorate the hospital capacity is 232 beds it serves psychotic patients of five department it consisted of four units for psychiatric male patients and one unit for psychiatric female patients and one addiction unit serve addict patient.

\section{Sampling:}

\section{Sample size and technique:}

Based on the previous studies that have examined the prevalence of substance abuse and found, the rate of drug dependence in Egypt amounted to $33 \%$ of the total population (incidence of substance dependency in Egypt, 2013). Sample size has been calculated using the following equation: $n=(\mathrm{z} 2 \times \mathrm{p} \times$ q)/D2 at power $80 \%$ and CI $95 \%$, the sample size was 80 .So A purposive sample of 80 adult patients who admitted in the above mentioned setting during the period of study one year and met the following inclusion and exclusion criteria, Hospitalized addict patients at any age, both sex, ready to participate in the study, aware and able to interact was recruited in the study.

\section{Instruments for data collection:}

The instruments that were used for data collection include the following:

The instrument I: Structured interview questionnaire:

The structured interview questionnaire was developed by the researcher based 
on scientific review of literature and revised by five professors in psychiatric nursing and medicine. It was divided into two parts:-

Part one includes:- It consisted of 16 items to elicit data about Sociodemographic characteristic of the studied addict patient and their families such as patients name, religion, sex, educational level, monthly income, marital status, demographic region.

Part two includes:- It consisted of 26 items that are assessing the Information about risk factor of addiction, and patient's perception and beliefs about addiction.

\section{The instrument II: Social Adjustment} rating Scale.

This tool was based on social Adjustment Scale originally developed by Abdel hamid and Abdel Wahab (1990) that was designed to assess social adjustment through different life domains. It was translated into Arabic and modified by the researcher who added 9. The instrument consists of 40 items. It was in the form of rating scale ranging from (1-3). The items were divided into four subscales. The were 8 items to assess the performance of the patient during treatment, 10 items to assess patient's activities of daily life, 12 items to assess patients social role performance, 5 items to assess patients personal hygiene, and 5 items to assess patients interesting in external events. Total score system for social adjustment were from (100) to (120) high, from (61) to (99) moderate and less than (61) Low.

The instrument III: Social Competence Scale.

Social Competence Scale was designed by Sarason, Hacker, \& Basham (1985) to assess the levels of social competence in a sample of teenagers and adult. It was translated in to Arabic by the researcher .The questionnaire was designed to assess the competence of addict in the society. The instrument contained 10 questions about his or her social skills, the social behavior in different situation, and social relationship. The candidate has to go through four point scale that is divided into (totally applicable, applicable, not applicable, and not applicable at all) it ranged from (0-4). Scoring system were from (35) to (40) high, from (25) to (34) moderate, from (15) to (24) mild and less than (14) low.

\section{Methods:-}

\section{Content validity:}

Before starting, the data collection all instrument were retested for its content validity by a group of experts in psychiatric nursing to check the relevance, coverage of the content and clarity of the questions. The required modification was carried out. Reliability: Test-retest reliability was applied for instrument (2 and 3). The instruments were proved to be strongly reliable (r. = 0.8222 , and 0.92) respectively. Ethical Consideration: A written acceptance was obtained from the subject to share in the study. The subjects who agreed to participate in the study were assured about confidentiality and anonymity of the study. They were informed about their right to withdraw from the study at any time without giving a reason. Pilot study: A pilot study was done on (8) addicts patients in Benha and Abassia psychiatric hospitals. The purpose of the pilot study was to test the applicability, feasibility and clarity of the instruments of data collection. As well as to find out any problems that might interfere with data collection. In addition, it served to estimate the approximate time required for interviewing the patients. After obtaining the result of the pilot study, the necessary modifications of instrument were done .Those patients were excluded from the actual study.

\section{Data collection procedures:-}


An official permission for data collection was obtained after submitting letter from the Dean of Faculty of Nursing, Benha University to General Director of the Mental Health Hospital in Benha and Al Abassia to obtain approval for data collection, the objectives and the nature of the study were explained.

All addict patients who fit in the inclusion criteria were approached by the investigator to fill the questionnaires according to the following steps:

1. The investigator started data collection by introducing herself to the participant.

2. Then a brief description of the purpose of the study and the data collection procedure was provided to each participant

3. Data collected were done through interviewing with the patients in hospital.

4. Each patient was individually interviewed.

5. Each interview lasted for 20-30 minutes, depending on the response of the interviewer.

6. The researcher started to collect the data from patients three days/ per week for each hospital.

7. Data collection process lasted for two months from (November 2015 to January 2016).

\section{Statistical analysis}

Data entry and statistical analysis were done using the statistical package for social sciences (SPSS version 16). Data were presented using descriptive statistics in the form of frequencies and percentages for qualitative variables, mean and standard deviation for quantitative variables. Qualitative variables were compared using the chi - square test, quantitative data were compared using $\mathrm{T}$ test or $\mathrm{F}$ test and correlation coefficient is used to measure the direction and strength of the correlation between variables. A significant level value was considered when P-value $<0.05$ and highly significant level value was considered when $\mathrm{P}$ value $<0.001$ while $P$ value of $>0.05$ indicated nonsignificant.

\section{Limitation of the study:-}

No limitation for this study

\section{Results}

Table (1): Risk factors that lead to addiction among the studied sample. This table show that the higher percentage of the risk factors for addiction among the studied sample are psychological problems, weak of will power ,bad friends, family problems, pressure at work, physical problem and cigarette smoking, (59\%, 45\%, 41\%, 39\%, 35\%, 32\%, $31 \%)$ respectively

Figure (1): levels of social competence among the studied sample. This figure shows that the higher percentage $(58 \%)$ are at moderate level of social competence compared to only $(3 \%)$ are at higher levels with statistical significant difference at $<0.001$.

Figure (2): levels of social adjustment among the studied sample. This figure shows that the higher percentage distribution of social adjustment are at moderate levels regarding all items of social adjustment except personal hygiene are at high levels with highly statistical significant difference at 0.00 . Near to three quarter $(71.25 \%)$ are at moderate levels of the total social adjustment with highly statistical significant difference at 0.00

Figure (3) Distributions of relapse among the studied sample. This figure reveals that more than half of the studied sample (55\%) have relapse. 
Table (2): Distributions of addict perception about addiction among the studied sample: this table reveals that the higher percentage of the addict perception about addiction among the studied sample are; help to, modify the mood, adjust ,solve the problems, concentrate and deal with others $(63 \%, .48 \%, 39 \%, 31 \%$ and $30 \%)$ respectively.

Table (3) Relationship between socio demographic characteristics and relapse among the studied sample. This table reveals that there is no statistical significant relationship between all socio demographic characteristics of the studied sample and relapse except gender there is a highly statistical significant difference at 0.038

Table (4): Relationship between addict perception about addiction and frequency of relapse. This table reveals that there is no statistical significant relationship between all items of addict perception about addiction and relapse.

Table (5): Relationship between family history of substance abuse and frequency of relapse .This tables reveals that there is only a highly significant relationship between drug abuse and the frequency of relapse at 0.011 .

Table (6): Correlation between social adjustment and social competence with frequency of relapse. This table reveals that there is insignificant negative correlation between frequency of relapse and mean score of social adjustment and social competence.

Table (1): Risk factors that lead to addiction among the studied sample

\begin{tabular}{|c|c|c|c|}
\hline \multicolumn{2}{|c|}{ Risk factor that lead to addiction } & \multirow{2}{*}{$\begin{array}{l}\mathbf{N} \\
32 \\
\end{array}$} & \multirow{2}{*}{$\begin{array}{c}\% \\
40.00 \\
\end{array}$} \\
\hline$\bullet$ & Physical problems & & \\
\hline$\bullet$ & Psychological problems & 59 & 73.75 \\
\hline$\bullet$ & Social problems & 24 & 30.00 \\
\hline • & The problems of the family and family disintegration & 39 & 48.75 \\
\hline$\bullet$ & Feeling of lonely & 23 & 28.75 \\
\hline • & Multiple responsibilities & 17 & 21.25 \\
\hline$\bullet$ & Exposure of sexual abuse & 8 & 10.00 \\
\hline$\bullet$ & Exposure to physical abuse & 7 & 8.75 \\
\hline$\bullet$ & Mixing with bad guys & 41 & 51.25 \\
\hline$\bullet$ & Tradition & 39 & 48.75 \\
\hline$\bullet$ & Weak of will power & 45 & 56.25 \\
\hline$\bullet$ & Increase income & 21 & 26.25 \\
\hline$\bullet$ & Cigarette smoking & 31 & 38.75 \\
\hline - & Street dealers & 22 & 27.50 \\
\hline$\bullet$ & Absence of family control & 16 & 20.00 \\
\hline$\bullet$ & Abuse of some psychiatric drugs & 4 & 5.00 \\
\hline$\bullet$ & Problems between the addict father's and his wife & 5 & 83.33 \\
\hline$\bullet$ & Problems between the adduct mother's and her husband & 2 & 40.00 \\
\hline & at work & 35 & 43.75 \\
\hline
\end{tabular}

Table (2): Addict perception about addiction among the studied sample as it perceived by them. 
The Risk Factors That Lead to Addiction and Relapse among Addicted Patients

\begin{tabular}{|c|c|c|}
\hline \multicolumn{3}{|c|}{ Addict perception about addiction } \\
\hline & $\mathbf{N}$ & $\%$ \\
\hline \multicolumn{3}{|c|}{ help to solve problems } \\
\hline - Yes & 39 & 48.75 \\
\hline - $\quad$ No & 41 & 51.25 \\
\hline \multicolumn{3}{|c|}{ help to concentrate } \\
\hline - $\quad$ Yes & 31 & 38.75 \\
\hline - $\quad$ No & 49 & 61.25 \\
\hline \multicolumn{3}{|c|}{ help to establish a good relationship with others } \\
\hline - $\quad$ Yes & 30 & 37.50 \\
\hline - $\quad$ No & 50 & 62.50 \\
\hline \multicolumn{3}{|l|}{ help to adjust } \\
\hline - Yes & 48 & 60.00 \\
\hline - $\quad$ No & 32 & 40.00 \\
\hline \multicolumn{3}{|c|}{ Help to modify the mood. } \\
\hline - Yes & 63 & 78.75 \\
\hline - $\quad$ No & 17 & 21.25 \\
\hline \multicolumn{3}{|c|}{ Help to deal with the top of power. } \\
\hline - $\quad$ Yes & 15 & 18.75 \\
\hline - $\quad$ No & 65 & 81.25 \\
\hline \multicolumn{3}{|l|}{ provides libido } \\
\hline - Yes & 27 & 33.75 \\
\hline - $\quad$ No & 53 & 66.25 \\
\hline
\end{tabular}

Figure (1): Distributions of the studied sample according to their levels of social competence. 
The Risk Factors That Lead to Addiction and Relapse among Addicted Patients

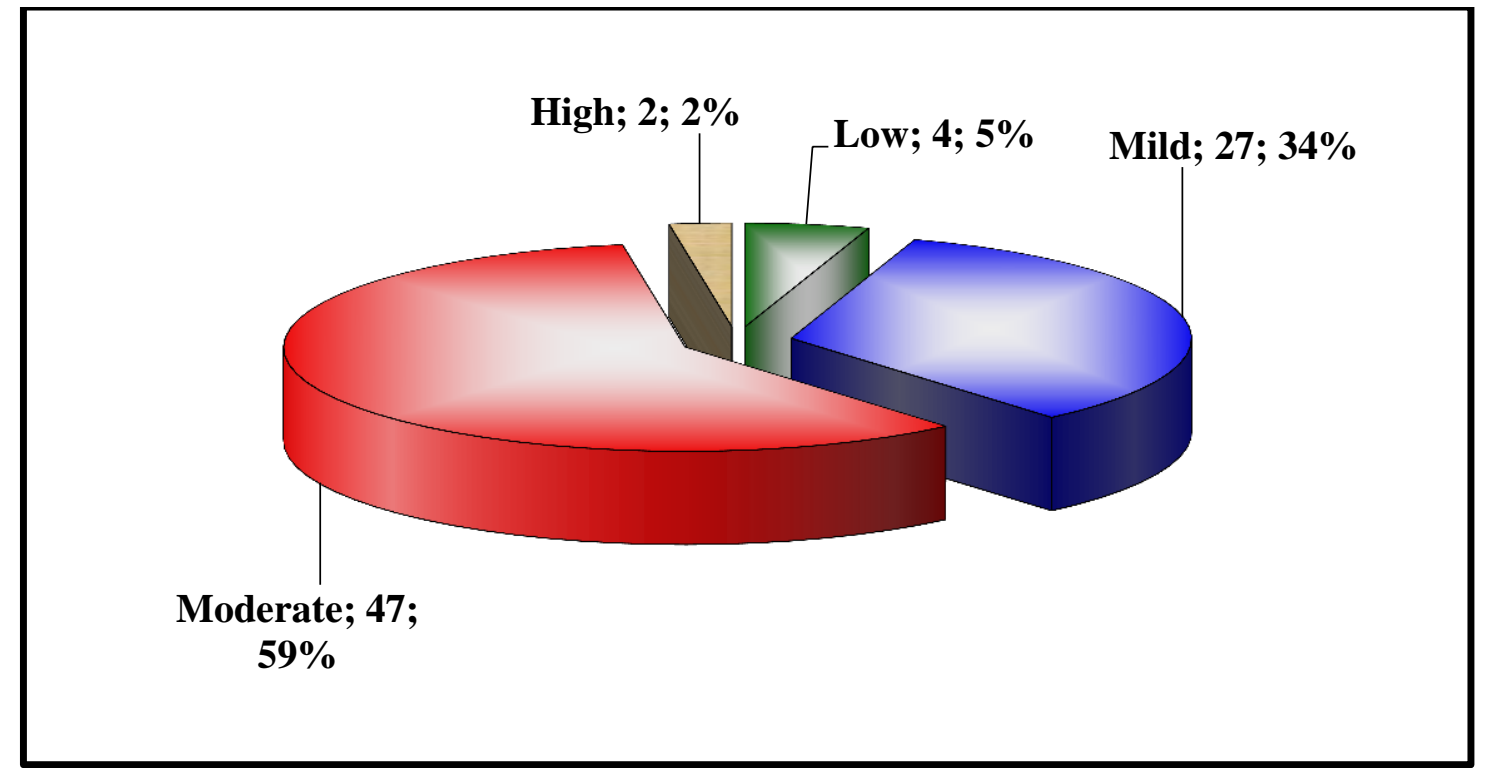

Figure (2): Distributions of the studied sample according to their levels of social adjustment

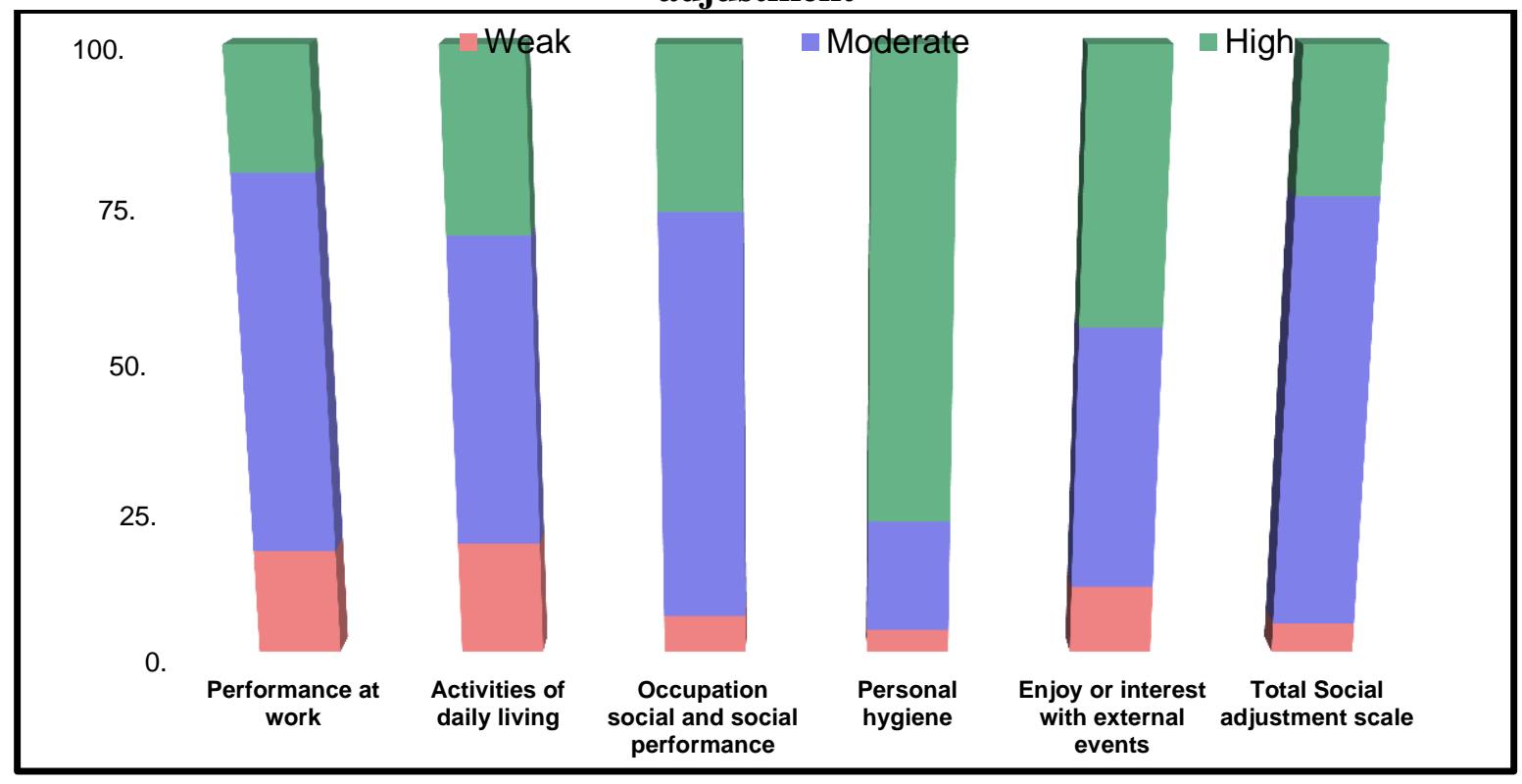

Figure (3) Distributions of the studied sample according to their relapse.

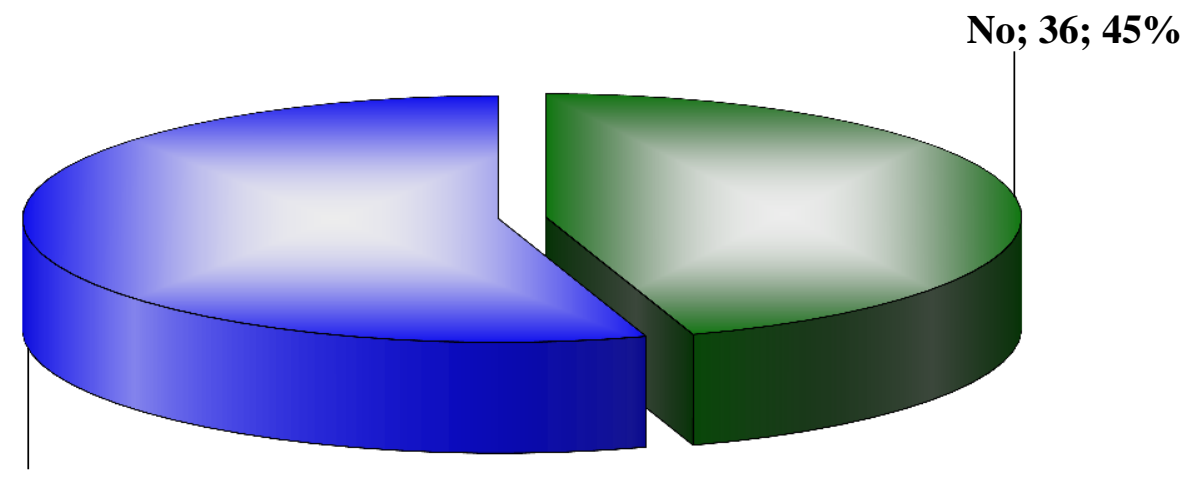

Yes; 44; 55\% 
Table (3): Relationship between socio demographic characteristics and relapse among the studied sample.

\begin{tabular}{|c|c|c|c|c|c|c|c|c|c|}
\hline \multirow{3}{*}{\multicolumn{2}{|c|}{ socio Demographic data }} & \multicolumn{6}{|c|}{ Relapse } & \multirow{2}{*}{\multicolumn{2}{|c|}{ Chi-square }} \\
\hline & & \multicolumn{2}{|c|}{ No } & \multicolumn{2}{|c|}{ Yes } & \multicolumn{2}{|c|}{ Total } & & \\
\hline & & $\mathbf{N}$ & $\%$ & $\mathbf{N}$ & $\%$ & $\mathbf{N}$ & $\%$ & $\mathrm{X}^{2}$ & P-value \\
\hline \multirow{3}{*}{ Age group } & $<25$ & 12 & $33.3 \%$ & 6 & $13.6 \%$ & 18 & $22.5 \%$ & \multirow{3}{*}{4.877} & \multirow{3}{*}{0.087} \\
\hline & $25-35$ & 15 & $41.7 \%$ & 27 & $61.4 \%$ & 42 & $52.5 \%$ & & \\
\hline & $>35$ & 9 & $25.0 \%$ & 11 & $25.0 \%$ & 20 & $25.0 \%$ & & \\
\hline \multirow{2}{*}{ Religion } & Muslim & 34 & $94.4 \%$ & 41 & $93.2 \%$ & 75 & $93.8 \%$ & \multirow{2}{*}{0.054} & \multirow{2}{*}{0.816} \\
\hline & Christian & 2 & $5.6 \%$ & 3 & $6.8 \%$ & 5 & $6.3 \%$ & & \\
\hline \multirow{2}{*}{ Gender } & Male & 23 & $63.9 \%$ & 37 & $84.1 \%$ & 60 & $75.0 \%$ & \multirow{2}{*}{4.310} & \multirow{2}{*}{0.038} \\
\hline & Female & 13 & $36.1 \%$ & 7 & $15.9 \%$ & 20 & $25.0 \%$ & & \\
\hline \multirow{4}{*}{ Education } & Not read or write & 3 & $8.3 \%$ & 3 & $6.8 \%$ & 6 & $7.5 \%$ & \multirow{4}{*}{0.106} & \multirow{4}{*}{0.991} \\
\hline & Basic education & 9 & $25.0 \%$ & 12 & $27.3 \%$ & 21 & $26.3 \%$ & & \\
\hline & $\begin{array}{l}\text { Intermediate } \\
\text { education }\end{array}$ & 18 & $50.0 \%$ & 22 & $50.0 \%$ & 40 & $50.0 \%$ & & \\
\hline & high education & 6 & $16.7 \%$ & 7 & $15.9 \%$ & 13 & $16.3 \%$ & & \\
\hline \multirow{4}{*}{ Marital status } & Married & 12 & $33.3 \%$ & 19 & $43.2 \%$ & 31 & $38.8 \%$ & \multirow{4}{*}{2.105} & \multirow{4}{*}{0.551} \\
\hline & Single & 18 & $50.0 \%$ & 15 & $34.1 \%$ & 33 & $41.3 \%$ & & \\
\hline & Widower & 1 & $2.8 \%$ & 2 & $4.5 \%$ & 3 & $3.8 \%$ & & \\
\hline & Absolute & 5 & $13.9 \%$ & 8 & $18.2 \%$ & 13 & $16.3 \%$ & & \\
\hline \multirow{3}{*}{ Residence } & urban & 19 & $52.8 \%$ & 16 & $36.4 \%$ & 35 & $43.8 \%$ & \multirow{3}{*}{2.444} & \multirow{3}{*}{0.295} \\
\hline & Rural & 2 & $5.6 \%$ & 2 & $4.5 \%$ & 4 & $5.0 \%$ & & \\
\hline & random areas & 15 & $41.7 \%$ & 26 & $59.1 \%$ & 41 & $51.3 \%$ & & \\
\hline \multirow{2}{*}{ Occupation } & Works & 26 & $72.2 \%$ & 30 & $68.2 \%$ & 56 & $70.0 \%$ & \multirow{2}{*}{0.154} & \multirow{2}{*}{0.694} \\
\hline & Does not work & 10 & $27.8 \%$ & 14 & $31.8 \%$ & 24 & $30.0 \%$ & & \\
\hline \multirow{3}{*}{$\begin{array}{l}\text { Monthly } \\
\text { income }\end{array}$} & Inadequate & 12 & 33.33 & 18 & 40.91 & 30 & 37.50 & \multirow{3}{*}{1.294} & \multirow{3}{*}{0.524} \\
\hline & Enough & 19 & 52.78 & 23 & 52.27 & 42 & 52.50 & & \\
\hline & $\begin{array}{c}\text { Adequate and the } \\
\text { savings of it }\end{array}$ & 5 & 13.89 & 3 & 6.82 & 8 & 10.00 & & \\
\hline
\end{tabular}

Table (4): relationship between addict perception about addiction and frequency of relapse

\begin{tabular}{|c|c|c|c|c|c|c|c|c|c|}
\hline \multirow{3}{*}{\multicolumn{2}{|c|}{$\begin{array}{l}\text { Items of adducts perception about } \\
\text { addiction }\end{array}$}} & \multicolumn{6}{|c|}{ Relapse } & \multirow{2}{*}{\multicolumn{2}{|c|}{ Chi-square }} \\
\hline & & \multicolumn{2}{|c|}{ No } & \multicolumn{2}{|c|}{ Yes } & \multicolumn{2}{|c|}{ Total } & & \\
\hline & & $\mathbf{N}$ & $\%$ & $\mathbf{N}$ & $\%$ & $\mathbf{N}$ & $\%$ & $\mathbf{X}^{2}$ & P-value \\
\hline \multirow{2}{*}{ helps to solve problems } & Yes & 17 & 47.22 & 22 & 50.00 & 39 & 48.75 & \multirow{2}{*}{0.061} & \multirow{2}{*}{0.805} \\
\hline & No & 19 & $\begin{array}{l}52.78 \\
\end{array}$ & 22 & 50.00 & 41 & 51.25 & & \\
\hline \multirow{2}{*}{ Helps to concentrate } & Yes & 16 & 44.44 & 15 & 34.09 & 31 & 38.75 & \multirow{2}{*}{0.893} & \multirow{2}{*}{0.345} \\
\hline & No & 20 & 55.56 & 29 & 65.91 & 49 & 61.25 & & \\
\hline \multirow{2}{*}{$\begin{array}{l}\text { Helps to establish a good } \\
\text { relationship with others }\end{array}$} & Yes & 17 & 47.22 & 13 & 29.55 & 30 & 37.50 & \multirow{2}{*}{2.642} & \multirow{2}{*}{0.104} \\
\hline & No & 19 & 52.78 & 31 & 70.45 & 50 & 62.50 & & \\
\hline \multirow{2}{*}{ Helps to adjust } & Yes & 24 & 66.67 & 24 & 54.55 & 48 & 60.00 & \multirow{2}{*}{1.220} & \multirow{2}{*}{0.269} \\
\hline & No & 12 & 33.33 & 20 & 45.45 & 32 & 40.00 & & \\
\hline \multirow{2}{*}{ Helps to modify mood. } & Yes & 30 & 83.33 & 33 & 75.00 & 63 & 78.75 & \multirow{2}{*}{0.834} & \multirow{2}{*}{0.361} \\
\hline & No & 6 & 16.67 & 11 & 25.00 & 17 & 21.25 & & \\
\hline \multirow{2}{*}{$\begin{array}{l}\text { Helps to deal with the top of } \\
\text { power. }\end{array}$} & Yes & 7 & 19.44 & 8 & 18.18 & 15 & 18.75 & \multirow{2}{*}{0.021} & \multirow{2}{*}{0.886} \\
\hline & No & 29 & 80.56 & 36 & 81.82 & 65 & 81.25 & & \\
\hline \multirow{2}{*}{ Provides libido } & Yes & 13 & 36.11 & 14 & 31.82 & 27 & 33.75 & \multirow{2}{*}{0.163} & \multirow{2}{*}{0.686} \\
\hline & No & 23 & 63.89 & 30 & 68.18 & 53 & 66.25 & & \\
\hline
\end{tabular}


The Risk Factors That Lead to Addiction and Relapse among Addicted Patients

Table (5): Relationship between family history and the frequency of relapse

\begin{tabular}{|c|c|c|c|c|c|c|c|c|}
\hline \multirow{2}{*}{\multicolumn{2}{|c|}{ Family history }} & \multicolumn{5}{|c|}{ The frequency of relapse } & \multicolumn{2}{|c|}{ Chi-square } \\
\hline & & One & Two & Three & Four or more & Total & $\mathbf{X}^{2}$ & P-value \\
\hline \multirow{2}{*}{ Smoking } & $\mathbf{N}$ & 30 & 11 & 10 & 6 & 57 & \multirow{2}{*}{4.856} & \multirow{2}{*}{0.183} \\
\hline & $\%$ & 83.33 & 61.11 & 62.50 & 60.00 & 71.25 & & \\
\hline \multirow{2}{*}{ Alcohol Abuse (addiction) } & $\mathbf{N}$ & 6 & 4 & 3 & 2 & 15 & \multirow{2}{*}{0.252} & \multirow{2}{*}{0.969} \\
\hline & $\%$ & 16.67 & 22.22 & 18.75 & 20.00 & 18.75 & & \\
\hline \multirow{2}{*}{ Drug Abuse (addiction) } & $\mathbf{N}$ & 12 & 13 & 9 & 2 & 36 & \multirow{2}{*}{11.065} & \multirow{2}{*}{0.011} \\
\hline & $\%$ & 33.33 & 72.22 & 56.25 & 20.00 & 45.00 & & \\
\hline \multirow{2}{*}{ Any psychological disease } & $\mathbf{N}$ & 3 & 1 & 1 & 1 & 6 & \multirow{2}{*}{0.262} & \multirow{2}{*}{0.967} \\
\hline & $\%$ & 8.33 & 5.56 & 6.25 & 10.00 & 7.50 & & \\
\hline
\end{tabular}

Table (6): Correlation between social adjustments, social competence with frequency of relapse

\begin{tabular}{|c|c|c|}
\hline \multirow{2}{*}{ Correlations } & \multicolumn{2}{|c|}{ The number OF relapse } \\
\cline { 2 - 3 } & $\mathbf{R}$ & P-value \\
\hline Social adjustment & -0.106 & 0.348 \\
\hline Social competence & -0.033 & 0.771 \\
\hline
\end{tabular}

\section{Discussion}

Addiction of substance abuse is becoming an increasing problem in Egypt. Many of studies were carried out in the country and showed that almost every Egyptian youngster at one time or another experiments with drugs, especially chemical ones (tramadol tablet) and cigarettes. The addiction Treatment Department at the Ministry of Health, reported that the rate of drug dependence in Egypt was $33 \%$ of the total population (incidence of substance dependency in Egypt, 2013).The proportion of drug abuse in Egypt exceeded the accepted international rates, between $5 \%$ to $7 \%$ (Control \&Treatment of Addiction and Abuse in the Egypt, 2013) .

The purpose of this study was to assess risk factor of addiction and relapse among addicted patients at Benha and Abassia Mental hospital. Regarding to demographical data for the substance abuse clients under the study, the finding of present study revealed that, clients were in the age group 25-35years. This result may be due to lack of interpersonal skills to cope with daily life stressors such as establishment of career and lack of involvement in more productive work, lack of having meaningful goal for life in the absence of future plan, limited financial resources and inability to meet demands of marriage. This result almost agrees with Asher \& Gask, (2010) who found that, most of addicted patients were between 25-35 years old, they mentioned that causes of addict on this age group were inability to cope with interpersonal stressors, failure to find satisfying job, lack of sense of meaning and lack of mutual relationship, delayed age of marriage, lack of protective housing and loss of family or social support.

As regard gender the present study clarified that, the majority of substance abuse clients were males. This result reflected the fact that female substance abusers rarely participate in rehabilitation programs to avoid negative comments 
and perception of the community attitude that labels them as immature, less tolerant to stressors, independent, irritable, and impulsive. This result consistent with Hosam, Mohammed \& Adel,( 2010), who explained that female substance abusers was considered as deviant, guilty, impulsive, easily irritable, less emotionally stable and less resistant to life stressors. So, consequently follow up health services were avoided by them and their chances for relapse were high

This result disagreed with Emad, et al., (2013) who found that women were more frequently treated from drug abuse than men do because women are more likely to engage in group counseling and receive more social support than men from a variety of sources such as families, friends, and coworkers. They also maintain social network that provides them with emotional support for their problems and encouragement to stop using drug.

In relation to marital status, finding of the current study found that one third of the cases were single. This can be related to the view that the addicted person were more likely to be isolated and be alone. This situation could be related to many reasons for example the addicts have shameful feelings, Also they don't deserve to live like others, or communicate with other. Besides social stigma there is some people think that they have sexual dysfunctions or problems.

This result was consistent with Anderson, et al., (2009) who explained, that most of addicted patients did not make marriage plans this increased their withdrawal from social contacts with other in order to keep their addictive behaviors private, avoid responsibilities and criticism from other spouse or reduce behavioral limitations.

According to the educational and job status this study shows that majority of the substance Abuse Clients have a job and completed their high school. This result agreed with Barrett, et al., (2012) who mentioned that, the majority of substance abuse clients were single, finished their secondary school and had a job.

Concerning family history of abuse, the result of the present study revealed that approximately more than one third of addicted patients understudy had a positive family history of abuse, mostly first degree relatives (e.g., fathers, brothers). They could act as models for addicted patients. Parents could provide children positive attitude toward substance abuse .Substances abuse could be rapid method for solving their problems they my strengthen their coping mechanism leading to enhancement of the development of maladaptive coping skills during exposure to daily life stressors.

This finding agreed with Barrett, et al., (2012) who found that, evidence a strong linkage between addicts' abusive behaviors and history of family abusive behaviors. So, Substance abuse is a family problem that affected biological and a psychological health. However there is a growing body of evidence that certain people (some children of alcoholics, for instance) are biologically at highest risk of becoming chemically dependent. Coping behaviors are learned within the context of the family. Children of substance-abusing parents may learn to cope with unpleasantness in their lives by taking substances into the body to change their mood state. Finally, it is a family problem because everyone in the family is profoundly affected by the behavior of alcohol and/or drug abuse Becker\& Curry, (2008).

This result was supported by a very recent study carried out by Sacks, (2008) who observed that family can enhance the risk of substance abuse relapse through a broad range of factors that characterize home of parents such as enhancing the availability of drugs, providing negative role models in terms of substance abuse or the use of drugs as a coping strategy which serves as a bad model for the 
development of maladaptive coping skills among offspring

The finding of This study revealed that, the psychological factor act as a key motivator to addiction, This could be due to the fact that addicted patients were experiencing a greater range of stressful life events resulting from a subsequent chain of bad events such as financial problems, delay or failure in academic education, lack of support system and lack of future planning and inability to overcome their difficulties due to lack of intrapersonal skills. This could cause patients relapse to substance use in order to eliminate the negative mood state and other powerful negative emotions (e.g. self-blaming, anxiety, tension, anger, irritation, boredom and fatigue, unresolved guilt feeling, sham, emptiness or void and lack of meaning or purpose of life).

These results were in accordance with Anshel, (2010) who reported that negative emotions as tension, impulsivity, anxiety etc. were more prevalent among relapsed patients due to stressful life events related to poor outcomes produced during their previous period of substance abuse (e.g. loss of job, lack of financial resources, lack of social support, separation from spouse or exposure to illegal problems).

In relation to family problem, this study revealed that the interrupted relationship between substance abusers and their families could foster the risk of substance abuse relapse. This might be due to exposure to an unharmonious relationship between patients and their families such as aggression, overprotection, persistent criticism, bad model, passive indifference, negative attitude (the patients are dealt with as guilty and as shameful source for the whole family). As well, rigid communication style at home atmosphere could produces emotional problems that could be attributed to lack of family connectedness, frequent confrontation with all family members, social and emotional support deprivation This result was consistent with Cockerill \& Riddington, (2010), who denoted that many patients relapsed to substance use due to their exposure to conflicting home atmosphere; lack of secure attachment to family members that produced serious emotional problems for patients, inability to express themselves, low self-esteem and inability to cope effectively with stressors.

This study finding indicated that psychological discomfort played an important role in developing relapse among substance abusers. In addition, the results showed that the main causes of substance abuse amongst addicted were lack of strong self -efficacy to avoid temptation, sensitivity and troubles in live. This could be due to the adverse influence of these discomforts on the patient's life that negatively interfered with their work, education, and social relationships which made them unable to fulfill major role obligations or carry up their most important responsibilities. These symptoms included insomnia, anxiety, lack of interest, reduced sexual drives, impaired judgment, extreme fatigue, lack of energy and lethargy, etc.). This caused patients' relapse to substance use in order to reduce physical compliance, promote feelings of adequacy and a greater sense of mastery and control.

On assessing the addict perception about addiction in the current study, findings indicated that the most perception was to modify the mood, helped to adjust, solve the problems, concentrate and deal with others. These findings were in agreement with a study carried out by Friedman and Glassman (2010). It was mentioned that, Most of the studied sample clarified that the addiction substances modified mood and helped to forget the stress.

Regarding relapse among the studied sample, it was found that more than half experienced relapse two or three times. 
This could be due to lack of social adjustment, interpersonal problems and poor social competence

This study was in line with Sacks, (2008) who studied therapeutic community for co-occurring disorders: founded that a summary of four studies, relapse was occurred more than two timeslday

In relation to social adjustment among the studied sample, this findings of the study represented that, nearly three quarters of the studied sample had moderate social adjustment, this may be due to that the addict tries to hide from others. This may be due to the emotional effect of substance abuse. Meanwhile This study was in agreement with Beck, (2007) who Studied "Psychiatric Disorders due to General Medical Conditions", founded that most of the studied sample have problems in their communication with the others

Findings of the present study showed that there was statistical significant relationship between relapse and gender. This could be due to difference in coping abilities with stress where female hade better coping abilities than males

This study was in agreement with the study of Van den, et al., (2010). They mentioned that relapse of drug abuse persons was affected gender and adjustment

As regards the Correlation between social adjustments, social competence with frequency of relapse, finding of this study revealed that there was insignificant negative correlation between frequency of relapse and both of social adjustment and social competence. This study was in an agreement with the study of Nader and Czoty, (2007), in their study "PET imaging of dopamine $D 2$ receptors in monkey models of cocaine abuse: genetic predisposition versus environmental modulation", they mentioned that there was negative relationship between relapse and both of social adjustment social competence and interpersonal communication problems.

Also, this study was in agreement with Breese, Sinha and Heilig, (2011), in their study "Chronic alcohol neuroadaptation and stress contribute to susceptibility for alcohol craving and relapse", they identified that, the marital affected social adjustment and social competence and relapse

The current finding clarified the relationship between family history and the number of relapse: it reported highly significant relationship between drug abuse and the frequency of relapse at 0.011

\section{Conclusion}

Based on the study finding it was concluded that. The most common risk factors for addiction and relapse were psychological problems, weak will power, bad friends, and family problems, pressure at work, physical problem and cigarette smoking.as will as perception about addiction. There is negative correlation between social adjustment, social competence and relapse.

\section{Recommendations}

Based upon the results of the current study the following recommendations are suggested:

Psychiatric nursing care programs and policies must be designed to manage the problems of patients having substance abuse.

Further studies should be done on a larger scope to assess risk factors that lead to addiction and relapse among addicts

\section{References}

Abdel Hamid, A\& Abdel Wahab, E (1999). Measuring social adjustment Among inpatient schizophrenic patients in Mansoura Unpublished Egyptian Doctorate Dissertation. 
Faculty of Nursing, Cairo University.

Alan, I. and Leshner. (2008). Oops: How Casual Drug Use Leads to Addiction, Available at: www.nida.nih.gov/.

Aldebot, S. and Weisman de Mamani, A.G. (2009). Denial and Acceptance Coping Styles and Medication Adherence in Schizophrenia. Journal of Nervous and Mental Disease, 197(8): 580-584.

Asher, C. and Gask, L. (2010). Reasons for illicit drug use in people with schizophrenia. Qualitative study. BMC Psychiatry, 10(94): 1-15.

Anderson, P., De Bruijn, A., Angus, K., Gordon, R., and Has tings, G. (2009). Impact of alcohol advertising and media exposure on adolescent alcohol use: a systemic review of longitudinal studies. Alcohol and Alcoholism, 44:229-43.

Anshel, M.H. (2010). A psychobehavioral analysis of addicted vs. non-addicted male and female exercisers. Journal of Sport Behavior, 14(2):145-154.

Barrett, E., Sussman, S., Smith, C., Roribach, L.A. and SparijtMetz，D. (2012). Motivational Interviewing for Adolescent Substance Use: A review of literature. Addictive Behaviour, 37, pp.: 1325-1334.

Beck, D.A. (2007).Psychiatric Disorders due to General Medical Conditions, Department of Psychiatry, University of Missouri-Columbia. http://www.umcpsychiatry.com/ medstudents/Psychiatryic.
Becker, S.J. and Curry, J.F. (2008). Outpatient Interventions for Adolescent Substance Abuse: A Quality of Evidence Review. Journal of Consulting and Clinical Psychology, 76 (4): 531-543.

Breese, G.R., Sinha, R., and Heilig, M. (2011).Chronic alcohol neuroadaptation and stress contribute to susceptibility for alcohol craving and relapse. Pharmacology Therapy, 129 (2): 149-71.

Cockerill, I.M. and Riddington, M.E. (2010). Exercise Dependence and Associated Disorders: A Review. Counseling Psychology Quarterly,

Control and treatment of addiction and abuse in Egypt, Hotline, (2013). incidence of substance Dependence in Egypt. Available leat: http://gate ahram. Org. e.g. $L$ News Content $/$ 13/54/325338/325338.

Emad, H., Noha, S., Aref, K., Albert, E. and Enab, D. (2013) The prevalence of alcohol and substance use among women in Cairo. National Addiction Research Program, 34 (3):155163.

Friedman, A. and Glassman, K. (2010). Family risk factors versus peer risk factors for drug abuse. A longitudinal study of an African American community, journal of Substance Abuse, 18: (3): 267275.

Greden, J. F. and Walters, A. (2013). Integrated text book of psychiatry: Relapse prevention in substance abuse, $\left(4^{\text {nd }} \mathrm{Ed}\right.$.). 
Millen Comp, Baltimore, pp. 357-370.

Hamdi, E., Sabry, N., Sedrac, A. and Refaat ,O. (2011). the national addiction survey - final report , Research unit of general secretariat of mental health, ministry of health, Egypt.

Hamid, E., Gawad, T., Khoweiled, A., Sidrak, A.E., Amer, D., Mamdouh, R., Fathi, H. and Loza, N. (2013). Lifetime prevalence of alcohol and substance use in Egypt: a community survey. Subst Abus, 34(2):97-104.

Hosam, E., Sawy, M., Abdel, H. and Adel, B. (2010). Gender Differences in Risks and Pattern of Drug Abuse in Egypt. Egypt J Neurol Psychiat Neurosurg, (47):1.

Incidence of substance dependence in Egypt, (2013). El youm Elsabaa Journal. Available at: http://www.youm7.com/New. Asp? New ID = 1068143\#umk 7 tdl woni.

Loren, B., William, V., Kippax, S. And Kristopher, J. (2010). The Role Of Physician And Nurse Attitudes In The Health Care Of Injecting Drug Users. Substance Use \& Misuse, 45:1007-1018.

Nader, M.A; and Czoty, P.W. (2007). PET imaging of dopamine D2 receptors in monkey models of cocaine abuse: genetic predisposition versus environmental modulation. Am J Psychiatry, 162 (8): 1473-82.

National Institute on Drug Abuse (NIDA), (2010). is part of the National Institutes of Health (NIH), a component of the U.S.
Department of Health and Human Services. Questions? http://drugabuse.gov/PODAT/fa qs.html.

Sacks, S. (2008). therapeutic community for co-occurring disorders: A summary of four studies. Journal of Substance Abuse Treatment, 34(1):112122, 2008.

Sarason, I.G and Sarson, B.R.,(1985). social competence scale, Anxiety and interfering though, their effect on social interaction.in Jons,W.,cheek,JM.\&Briggs, S .; Shyness, perspectives on research and treatment,plenum.press.New York and landon,227-238

United Nations Office on Drugs and Crime UNODC, (2012). World Drug Report 2012, United National Office for Drug Control and Crime Prevention.

Www,Unodc, org/documents/dataandnalysis/ WDR2012 web small pdf

United Nations Office on Drugs and Crime (UNODC), (2010). World drug report, New York, United Nations office on Drugs and Crime.

Van den, M.C., Spijker, S.,Smit, A.B., and De Vries, T.J. (2010). Prefrontal cortex plasticity mechanisms in drug seeking and relapse. Neurosci Biobehav, 35 (2): $276-84$.

Winstock, A. (2014). Global drug survey 2014 Findings: Reflection on the results of the world's biggest ever drug survey. 